\title{
Littérature et identité (état des lieux et tâches à remplir)
}

Literature and identity: present situation and tasks

Kirjandus ja identiteet: praegune olukord ja ülesanded

János Pusztay

Traducteur : Eva Toulouze

\section{(2) OpenEdition}

Journals

Édition électronique

URL : https://journals.openedition.org/efo/3456

DOI : 10.4000/efo.3456

ISSN : 2275-1947

Éditeur

INALCO

Édition imprimée

Date de publication : 1 janvier 2014

ISBN : 978-2-343-05394-3

ISSN : 0071-2051

\section{Référence électronique}

János Pusztay, « Littérature et identité (état des lieux et tâches à remplir) », Études finno-ougriennes [En ligne], 46 | 2014, mis en ligne le 04 novembre 2015, consulté le 08 juillet 2021. URL : http:// journals.openedition.org/efo/3456; DOI : https://doi.org/10.4000/efo.3456

Ce document a été généré automatiquement le 8 juillet 2021.

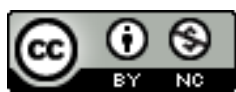

Études finno-ougriennes est mis à disposition selon les termes de la Licence Creative Commons Attribution - Pas d'Utilisation Commerciale 4.0 International. 


\title{
Littérature et identité (état des lieux et tâches à remplir)
}

\author{
Literature and identity: present situation and tasks \\ Kirjandus ja identiteet: praegune olukord ja ülesanded
}

János Pusztay

Traduction : Eva Toulouze

\section{Le rôle de la littérature}

1 Pour beaucoup de peuples, la littérature a joué un rôle important dans le long processus de formation ethnique. C'est grâce à la littérature que des peuples auparavant inconnus sont devenus célèbres : il suffit de penser au rôle de l'épopée finnoise, le Kalevala, dans la première moitié du xix siècle. Cet exemple est particulièrement intéressant à plus d'un égard. En effet, les facteurs qui sont en jeu sont de ceux qu'on a tendance à considérer aujourd'hui comme anachroniques. Deux remarques à ce sujet :

- En tant que genre, l'épopée avait déjà fait son temps dans la première moitié du XIX siècle. Pourtant, l'épopée finnoise permettra l'éveil de la conscience et la formation de l'identité finnoises, c'est à dire, en fin de compte, conduira à l'indépendance de la Finlande.

- Le rôle d'un seul homme. Elias Lönnrot, après ses études universitaires, deviendra médecin dans le Nord de la Finlande, au village de Kajaani (qui, dans la perspective de l'époque, était « derrière le dos de Dieu ») ; alors qu'il n'y avait ni chemin de fer, ni avion, ni téléphone ni Internet, il parvint à collecter des matériaux d'un intérêt capital pour l'épopée finnoise et à les organiser. Grâce à l'épopée, il devint la figure de proue de la vie intellectuelle finnoise. De plus, il établit plusieurs glossaires de terminologie spécialisée et compila le dictionnaire le plus riche de la langue finnoise (seul le Nykysuomen sanakirja, édité dans un passé récent, contient plus de mots que le dictionnaire finnois-suédois de Lönnrot).

C'est grâce à la parution du Kalevala que la Finlande s'est fait connaître dans le monde.

2 En même temps, l'épopée a provoqué une réaction créative en chaîne. 
3 C'est sous son influence que naquit en Estonie l'idée de créer une épopée estonienne, qui fut établie sous le nom de Kalevipoeg par Kreutzwald - sur la base d'un travail préalable fait par Faehlmann - au début de la deuxième moitié du xix siècle. À son tour, l'épopée estonienne servit de modèle à l'épopée lettonne, établie sous le titre de Lāčplēsis par Andrejs Pumpurs en 1888. C'est également inspiré par le Kalevala, dont il avait appris l'existence par les rapports d'Antal Reguly, que János Arany, en Hongrie, écrivit sa trilogie hunnique. De plus, je pense ne pas me tromper en posant l'hypothèse que les épopées qui ont paru les unes après les autres, ces dernières décennies, chez les peuples finno-ougriens de Russie, sont nées elles aussi dans la lignée du Kalevala.

\section{La situation actuelle}

4 La situation actuelle des peuples finno-ougriens de la Fédération de Russie ressemble jusqu'à un certain point à celle des Estoniens, des Finnois et des Hongrois au début du xIX ${ }^{e}$ siècle. En même temps, leurs destinées présentent quelques divergences essentielles.

5 Mon expérience me montre que dans les républiques finno-ougriennes de Russie, en dépit de l'existence de lois sur la langue, sur la culture, sur l'éducation, les problèmes restent sérieux. Les lois ne fonctionnent que partiellement. Mais la question essentielle n'est pas là. La question essentielle est de savoir si les peuples finno-ougriens euxmêmes tiennent à leur langue et à leur culture. Il me semble que leur rapport à ces valeurs se manifeste plus en paroles qu'en actes. Plutôt qu'une conscience nationale, ce qui se développe chez beaucoup est une conscience générale, russienne. Le processus de formation de l'homo sovieticus a été remplacé, avec la désagrégation de l'Union soviétique, par l'exigence de formation d'un homo russlandicus.

6 Ce processus a des effets sur les traditions orales des peuples finno-ougriens, sur leur manière de présenter leurs chants et leurs danses, qui ressemblent de plus en plus au style de l'ensemble Mojseev et s'éloignent des traditions finno-ougriennes d'origine.

7 Les traductions russes des œuvres littéraires finno-ougriennes ne sont souvent que des adaptations méconnaissables des œuvres originales. L'explication en est simple : il faut les « élever ", dit-on, pour qu'elles atteignent le niveau de la littérature russe, ce qui leur fait perdre leur spécificité, leur saveur originale, leur style.

\section{Que faire?}

- Il convient de créer les conditions pour que des œuvres littéraires puissent continuer à être écrites dans les langues finno-ougriennes de Russie.

- Il convient de faire tout particulièrement attention à la littérature pour les enfants et les jeunes. Dans l'œuvre de popularisation de langues menacées, la littérature de jeunesse est un outil essentiel qui peut permettre aux jeunes de se tourner éventuellement à nouveau vers la langue de leurs parents ou de leurs grands-parents.

- Il faut faire connaître les littératures des peuples finno-ougriens à la communauté finnoougrienne par des traductions mutuelles.

- Il faut traduire les œuvres les plus précieuses de la littérature mondiale, y compris russe, dans les langues finno-ougriennes de Russie, si possible depuis l'original et non par l'intermédiaire du russe. 
- Il faut organiser systématiquement des rencontres entre les écrivains et leurs lecteurs, dans les écoles et dans les maisons de la culture, dans les villes comme à la campagne.

- Il faut faire en sorte que les œuvres littéraires qui paraissent dans des langues finnoougriennes arrivent jusqu'aux lecteurs. À l'heure actuelle, la privatisation de la distribution des livres fait que ceux-ci n'arrivent pas jusqu'aux localités rurales, car le faible nombre d'exemplaires demandés fait de leur distribution une activité non rentable.

- Il faut organiser régulièrement et systématiquement des séminaires de traducteurs. C'est ce que font les Finnois pour leurs traducteurs finno-ougriens venus de Russie. La condition préalable à la traduction est la connaissance des langues. Il faut introduire dans les universités des Républiques finno-ougriennes l'enseignement des autres langues de la famille. Ceci n'est pas coûteux si l'on fait appel aux conditions techniques contemporaines : la visioconférence permet de réaliser la mobilité virtuelle (la faculté des lettres de l'université de Hongrie Occidentale /Szombathely/ a élaboré dans le cadre de la chaire d'ouralistique un enseignement à distance sur la base d'Internet, et la visioconférence permet un enseignement efficace des langues, enrichi de contacts interactifs. Par cette méthode, on pourrait résoudre la question de l'enseignement mutuel des langues finnoougriennes sans la présence d'un enseignant sur place.)

- Il faut faire connaître au monde la littérature des peuples finno-ougriens de Russie, d'une part afin d'enrichir la culture mondiale, d'autre part pour accroître le prestige des langues et des cultures des peuples finno-ougriens à leurs propres yeux.

8 Les premiers pas ont été faits - dans le cadre d'une conception réfléchie et non, comme avant, au petit bonheur la chance - en Estonie, en Finlande comme en Hongrie, à des échelles et avec une portée diverses. Il suffit de penser au programme grandiose mis en œuvre en Estonie par Arvo Valton, dans le cadre duquel quelques dizaines d'anthologies, meilleures les unes que les autres, ainsi que des œuvres d'auteurs, ont vu le jour en estonien, sans compter la collection de poèmes en quatre langues comportant entre autres des traductions mot à mot en russe et en anglais. En Finlande, nous devons des traductions de littératures finno-ougriennes de Russie d'une part à Raija Bartens, d'autre part à l'association Castrén. En Hongrie, Péter Domokos et Gábor Bereczki ont travaillé à de nombreuses anthologies littéraires, et il existe même une anthologie de toutes les littératures finno-ougriennes. Dans ces dernières décennies, Katalin Nagy a également publié quelques volumes. La chaire d'ouralistique de l'université de Hongrie Occidentale, en plus des collections dédiées à la linguistique, publie la collection Minoritates mundi - Literatura, qui comprend pour la plupart des éditions bilingues, à ce jour au nombre de vingt-cinq, dont vingt-deux consacrées aux littératures finnoougriennes (les trois restantes donnant un aperçu de la littérature lettone contemporaine). C'est ainsi que nous avons édité dans cette collection la cinquième traduction hongroise du Kalevala, plusieurs volumes finnois et estoniens, mais aussi des anthologies des littératures mordve, komie, carélienne et vepse, ainsi que des œuvres d'auteurs oudmourtes, maris et nénetses.

9 Je suis enchanté de voir que parmi les jeunes originaires de Russie faisant leurs études aussi bien dans les Républiques finno-ougriennes qu'à l'étranger, par exemple en Estonie, il y en a qui choisissent la voie de la création littéraire dans leur langue, et de plus choisissent de relire, éditer et populariser les œuvres de leur littérature. Par exemple, en 2012, les étudiants maris en Estonie ont participé à la parution d'une anthologie des jeunes poètes maris en traduction estonienne, finnoise et hongroise. 
Ainsi, on peut espérer que la solidarité finno-ougrienne ouvre aux littératures finnoougriennes de qualité la porte du monde non finno-ougrien.

\section{Quelques mots sur l'avenir, d'un point de vue hongrois}

En 2008 a été créée, avec un soutien gouvernemental, une institution appelée Collegium Fenno-Ugricum, sur la rive nord du lac Balaton, dans la petite ville de Badacsonytomaj.

Cet institut, doté d'une bibliothèque et d'une salle de visioconférence, a comme objectifs :

- d'organiser des projets scientifiques destinés à aider au développement des langues finnoougriennes (par exemple l'élaboration de la terminologie nécessaire dans l'enseignement ou dans la vie politique) ; ceci a débouché sur le programme Terminologia scholaris, mis en œuvre en 2010-11, dans le cadre duquel nous avons élaboré le lexique spécialisé pour cinq langues (erza, komi, mari, mokcha, oudmourte) et dix matières scolaires (langue maternelle, littérature, histoire, sciences sociales, géographie, mathématiques, physique, biologie, chimie, informatique), en coopération avec les spécialistes des universités de Syktyvkar, de Saransk, de Joškar Ola et d'Iževsk. Nous avons publié sur ces bases les cinquante dictionnaires terminologiques correspondants (dont la structure est la suivante : le terme dans la langue finno-ougrienne en question / le terme en russe / l'explication dans la langue finno-ougrienne, avec à la fin un index russe / finno-ougrien);

- de contribuer à la diffusion des connaissances sur les communautés finno-ougriennes dans des langues diverses, dont les langues finno-ougriennes elles-mêmes. C'est la collection Bibliotheca Fenno-Ugrica qui joue ce rôle : elle comprend à ce jour de petites monographies de vulgarisation scientifique présentant sept peuples finno-ougriens (les Caréliens, les Komis, les Komi-Permiaks, les Maris, les Mordves, les Oudmourtes, les Vepses), dans les langues de ces peuples (pour les Caréliens en deux variantes du carélien, pour les Mordves en erza et en mokcha) ainsi qu'en russe (sur la base de cette dernière version il sera possible de les traduire dans n'importe quelle autre langue finno-ougrienne ou langue du monde);

- d'éditer de la littérature finno-ougrienne en hongrois ou de la littérature hongroise dans les langues finno-ougriennes. C'est le rôle du programme LiteratUral, dans le cadre duquel quatre ouvrages ont été publiés : un oudmourte (Nadi Muš), un mari (Albertina) et un komi (Nina Obrezkova), ainsi qu'une anthologie d'Attila József en oudmourte ;

- d'organiser des cours, des universités d'été, des formations ;

- d'être rattaché au travail de l'Association des universités finno-ougriennes (le projet terminologique évoqué ci-dessus s'est déroulé dans le cadre de cette association).

\section{En conclusion}

11 La littérature peut-elle contribuer au développement et au renforcement de l'identité ? Je suis convaincu qu'on peut répondre à cette question par l'affirmative, mais à condition que :

- les prérequis politiques et professionnels (par exemple linguistiques) nécessaires à la création littéraire soient réunis ;

- le besoin de la création littéraire se fasse sentir ;

- les littératures finno-ougriennes préservent leur spécificité et ne se fondent pas dans d'autres littératures;

- la langue se maintienne et évolue. 


\section{BIBLIOGRAPHIE}

PUSZTAY János, 2001, A Kalevala - egy eposz és a nyelv. (A kultúra és az identitás kérdései)”, A Kalevala végleges szövege 150 éves (A Magyar Tudományos Akadémián 1999. szeptember 14-én rendezett jubileumi tudományos ülés előadásai), Specimina Fennica IX, Savariae/Szombathely, p. 55-62.

PUSZTAY János, 2008, «ЛИТЕРАТУРА И САМОСОЗНАНИЕ», БУДУЩЕЕ ФИННО-УГОРСКИХ ЛИТЕРАТУР. ТВОРЧЕСТВО МОЛОДЫХ АВТОРОВ, МАРИЙ САНДАЛЫК - МАРИЙСКИЙ МИР, ЙОШКАР ОЛА.

\section{RÉSUMÉS}

Cet article programmatique du président de l'association des littératures finno-ougriennes met l'accent sur l'importance de la littérature dans l'affirmation des identités finno-ougriennes et se penche sur les tâches à remplir pour qu'elle puisse réellement jouer son rôle.

This is a programme article by the chairman of the Association of Finno-Ugric literatures, which emphasises the importance of literature for Finno-Ugric ethnic identities and reflects on the tasks to be achieved in order to play fully its function.

Selles programmaatilises artiklis rõhutab soome-ugri kirjanduste ühingu president kirjanduse tähtsust soome-ugri rahvusindentiteetide kinnitamises. Ta loetleb ülesanded, mida ta peab täitma, et mängida täiel määral oma rolli. 


\section{INDEX}

Mots-clés : épopée, identité nationale, politique linguistique, vie littéraire, Association Castrén, homo sovieticus, Kalevala, Kalevipoeg, Lāčplēsis, Nykysuomen sanakirja

nomsmotscles Caréliens, Estoniens, Finnois, Hongrois, Komis, Komis-Permiaks, Maris, Mordves, Nénetses, Oudmourtes

disciplines estonien, erza, finnois, hongrois, letton, komi, mari, mokcha, oudmourte, russe, suédois

motscleset eepos, rahvusidentiteet, keelepoliitika, kirjanduselu

Keywords : ethnic identity, epic, language policy, literary life, beginning of the 21st century, Estonian, Erzya, Finnish, Hungarian, Latvian, Komi, Mari, Moksha, Russian, Swedish, Udmurt, Carelians, Finns, Komi-Permyak, Mordvinians, Nenets, Veps, Badacsonytomaj, Balaton, Estonia, Finland, Hungary, Izhevsk, Kajaani, Russia, Saransk, Syktyvkar, Szombathely, Yoshkar-Ola, Literature

Index géographique : Estonie, Finlande, Kajaani, Hongrie, Badacsonytomaj, Balaton (lac), Szombathely, Fédération de Russie, Républiques finno-ougriennes, Mari-El (République), Mordovie (République), Saransk, Oudmourtie (République), Iževsk, Komi (République), Syktyvkar Index chronologique : XXIe siècle

Thèmes : littérature 